\title{
The Transformation of Monopoly Game: Learning Media to Improve Students' Creativity and Interest in Learning
}

\author{
Atika Dinna Hastanti \\ English Education Department, Faculty of Education and Teacher Training, Universitas Tidar \\ Jalan Kapten Suparman Nomor 39, Kecamatan Magelang Utara, Kota Magelang, 56116, Jawa Tengah, Telp. (0293) 364113 Fax. (0293) 362438 \\ surel: admin@untidar.ac.id
}

\begin{abstract}
This study aims to determine and applying how effective the design of The Transformation of Monopoly Game as a learning media in order to increase students' creativity and interest in learning. Technological progress has been rapid development in various fields such as social, political, cultural, economic and even education. Due to technological advances often cause trends and addictions to technology, especially among students. Based on a Study funded by UNICEF (United Nations Children's Fund) and carried out by the Ministry of Communication and Information by tracking online activities of a sample of children and adolescents aged 10-19 (as many as 400 respondents). The results of this study state the use of social media and digital become an integrated part in the daily lives of Indonesian young people. The study found that $98 \%$ of the children and adolescents surveyed knew about the internet and that $79.5 \%$ of them were internet users. This research uses descriptive method and action research. Descriptive method is used to describe the phenomena that are taking place now or in the past, and collect data from journals, book, as well as other sources. Then by applying the action research method which research objects use in the learning process. Through this media students not only play but also learn, so this can find out how effective The Transformation of Monopoly Game is as a learning medium in order to increase students' creativity and interest in learning.
\end{abstract}

Keywords: Games, Interest, Learning Media, Technology Addiction.

\section{INTRODUCTION}

The world is undergoing a profound change, the impact is a result of the rapid progress of the digital world. This progress by social science experts is often referred to as the era of disruption, in this case an era in which all sectors come to feel the impact, both the health sector, economic, social, political, cultural and education sectors also feel the impact of the transition to digital progress. Therefore, with the progress of this era of disruption, it can boost the effectiveness of education in Indonesia.

The effectiveness is based on BPS (Central Statistics Agency) data on Education Process Results in 2018 showing the percentage of students who went to grade 8 Junior High School is $96.01 \%$ higher than the percentage of students who went to grade 9 Junior High School which is $93.97 \%$. Different patterns occur at the level of high school/equivalent where students who go up to grade 11 in Senior High School are 92.40\% lower than students who go up to grade 12 Senior High School which is $92.59 \%$. It is likely that this happened because the students were in the early adolescent phase (13-15 years old) who were in the process of developing their psychological experience in the process of environmental adaptation and learning. Therefore, in this case effective learning at that age will determine the progress of learning outcomes.

This way of learning can be applied in various ways one of them through traditional games. Noted from the total number of children in Indonesia, less than $38 \%$ still know traditional dolanan. The history has also been recorded since 1938, where $\mathrm{H}$. Overbeck documented 690 traditional Indonesian puppets. Traditional game developed for a long time, the game is loaded with national cultural values. However, along with the development of the age of traditional games is increasingly forgotten by children. Therefore, it is necessary to transform the traditional game into a more modern one without having to eliminate the nation's cultural value that is based on semi-traditional puppetry especially in the application of learning media.

The implementation of games in the educational process can provide a new experience for students, especially the game itself can stimulate creativity and fun for students. The game in the learning process does not have to be expensive, the most important is the students' understanding and comprehension of the learning material delivered through the game can be well received by students. This is in order to realize educational achievements and to optimize learning itself.

\section{MATERIALS AND METHODS}

\section{Study area}

The world is experiencing significant progress due to technological advances. This also affects all sectors, including the health, economic, social, political, cultural and educational sectors, as well as the impact of the digital transition transition. This change is called the era 
of disruption or in other words the era of many changes, the impact also varies from the disruption of a sector and even experience extinction, but also many are helped by a change or innovation. Renald Kasali concluded that the era of disruption was a time that was threatening and had severe challenges in human life, and people who were unable to adapt to change would naturally experience many difficulties in reducing the tide of daily life that was full of change and full of competition (Kasali, 2018).

In this era of disruption, education can balance the demands of civilization. However, the world of education itself inevitably has to be able to adapt to changing times, education as a means of channeling knowledge so that people can balance themselves with the progress of this civilization. Moreover, education has become one of the important sectors in preparing Indonesia's young generation who have competitiveness.

The effectiveness of student learning can be measured from the results of the learning process and the learning process itself for students. Recorded in BPS (Central Statistics Agency) data the results of the 2018 education process for Elementary School level have experienced ups and downs. The results of the education process for students up to grade $2^{\text {nd }}$ elementary school around $93.08 \%$, while grade $3^{\text {rd }}$ elementary school reaches $94.54 \%$, grade $3^{\text {rd }}$ elementary school reaches $94.91 \%$, but grade $5^{\text {th }}$ elementary school has decreased by around $94.17 \%$ and grade $6^{\text {th }} \mathrm{SD}$ experienced an increase of around $95.35 \%$.

Then the same for the Junior High School and high school levels also experienced ups and downs, the data showed the percentage of students who went to grade 8 in Junior High School was $96.01 \%$ higher than the percentage of students who went to grade 9 in Junior High School which was $93.97 \%$. Different patterns occur at the level of high school /equivalent where students who go up to 11 in Junior High School are 92.40\% lower than students who go up to 12 in Junior High School which is $92.59 \%$. It is likely that this happened because the students were in the early adolescent phase (13-15 years old) who were in the process of developing their psychological experience in the process of environmental adaptation and learning. Therefore, in this case effective learning at that age will determine the progress of learning outcomes. However, it cannot be said to be effective if students cannot understand or even apply their knowledge from the learning process that they can during the learning process.

One of the causes of the decline of traditional games is the result of technological advancements which in turn create a variety of more interesting services, such as television, online games, video games and others. Therefore, it is necessary to transform the traditional game into a more modern one without having to eliminate the nation's cultural value that is based on semi-traditional puppetry especially in the application of learning media. That can causes not only about tendency towards technology but can also reduce children's creative thinking. Then, it is necessary to encourage improvement of habits in children, especially in the learning process at school.

\section{Procedures}

In this research has some steps that included on method and materials. That steps are geting information from respondents by using google form and then the transformation of monopoly game. The steps are as follows:

\section{Geting Opinion from Respondents By Using Google Form}

The questionnaire of Google form is used, because it is convenient to accesses. This is a tool that allows collecting information from respondents via a personalized survey or quiz.

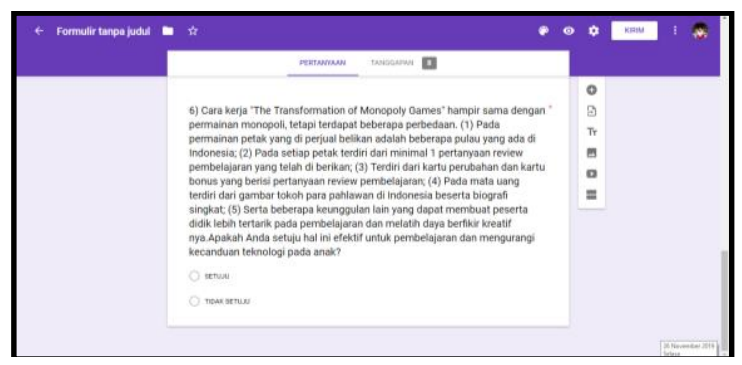

Figure 1. Geting Opinion From Respondents By Using Google Form.

This steps we find the respondent to get information about effectiveness survey of the transformation monopoly game. The respondents are from, the link of Google Form is shared through social media such as WhatsApp application. It is shared for two days or a long time until get the many respondents. The questions in the from are about the effectiveness survey of the transformation monopoly game, the developments of technological, addicted to the use of technology and effectiveness the transformation of monopoly game. The answers of some that questions, which are about agreement or not and responses and suggestions regarding this research.

\section{The Parts of Transformation Monopoly Game}

In this steps are consists, what the parts of transformation monopoly game look like, in each parts are a unity that cannot be separated there are:

a. The board game that consists of several blocks of regional blocks.

b. The miniature houses and people as movers and objects of the game.

c. The exchange cards and bonus cards.

d. The question sheet cards in each region.

e. Play money as a driver for the survival of the game. 


\section{The Combination of Respondent Responses and Transformation of Monopoly Game}

In this step the results of respondents who already filled the Google Form question thath can get the point of problem solving. It is about the hopes of respondents about the transformation of monopoly game, the problem about trends in the use of technology that can cause technology addiction. This can be obtained the relationship between the effectiveness transformation of monopoly game with this problems. This game is used as a learning medium in schools.

\section{Data analysis}

In this section of the date analysis, the researcher use questionnaire to looking for the real information. That steps are geting information from respondents by using google form and then the transformation of monopoly game. Google Forms is a survey administration that is included in the Google Drive office suite along with Google Docs, Google Sheets, and Google Slides. Forms features all of the collaboration and sharing features found in docs, sheets, also slides. The questionnaire of Google Form is used, because it is convenient to accesses. This is a tool that allows collecting information from users via a personalized survey or quiz. The spreadsheet is populated with the survey and quiz responses. This the question that the researcher used:

1. Technological progress in this era can no longer be denied its existence. If this cannot be resolved properly will it cause more negative impacts?

2. In your opinion, what are the negative and positive impacts of technological progress?

3. Due to the tendency to use technology often has an impact on technology addiction, this does not only occur among adolescents, adults and even children. So this can inhibit children's growth and development and thought power. Do you agree?

4. In your opinion, what are the negative effects of technology addiction on children?

5. One way to overcome technological addiction is to invite children to play outside and while learning. Here we suggest a prototype of a monopoly game reform that we named "The Transformation of Monopoly Games". This is a method/learning model that can be used by parents/teachers to evaluate the child or students to be able to play and while learning and can train their creative thinking. Do you agree the transformation of this game can reduce technological addiction in children?

6. The workings of "The Transformation of Monopoly Games" are almost the same as monopoly games, but there are some differences:

1) In the game plot which is traded are several islands in Indonesia;

2) Each plot consists of at least 1 review question that has been given;

3) Consists of change cards and bonus cards containing learning review questions;
4) Currency consists of images of heroes in Indonesia and brief biographies;

5) As well as several other advantages that can make students more interested in learning and practicing their creative thinking power. Do you agree this is effective for learning and reducing technology addiction in children?

The target in this study was the public. Some reasons why the researchers only take the scope of public, that reasons are as follows:

1. Increasing sensitivity to environmental problems.

2. Raising awareness not to use technology improperly.

3. Becoming an agent of change in environmental problems or be a good example of change.

4. Teaching young people not to depend on technological ease.

5. Inviting the younger generation to always think critically and creatively.

\section{RESULTS AND DISCUSSION}

Result-1 (The Questionnaire and Ways of Working The Transformation Monopoly Games)

In this steps are consists, what the parts of transformation monopoly game look like, in each parts are a unity that cannot be separated. In this procedures are consists from some part of the prototype design, there are:

\section{The Response From Respondents Through Google Form}

In this section of the date analysis, the researcher use questionnaire to looking for the real information. That steps are geting information from respondents by using google form and then the transformation of monopoly game. Google Forms is a survey administration that is included in the Google Drive office suite along with Google Docs, Google Sheets, and Google Slides. The question questionnaire in google form are about the effectiveness survey of the transformation monopoly game, the developments of technological, addicted to the use of technology and effectiveness the transformation of monopoly game. The answers of some that questions, which are about agreement or not and responses and suggestions regarding this research.

2. Ways of Working The Transformation Monopoly Games 


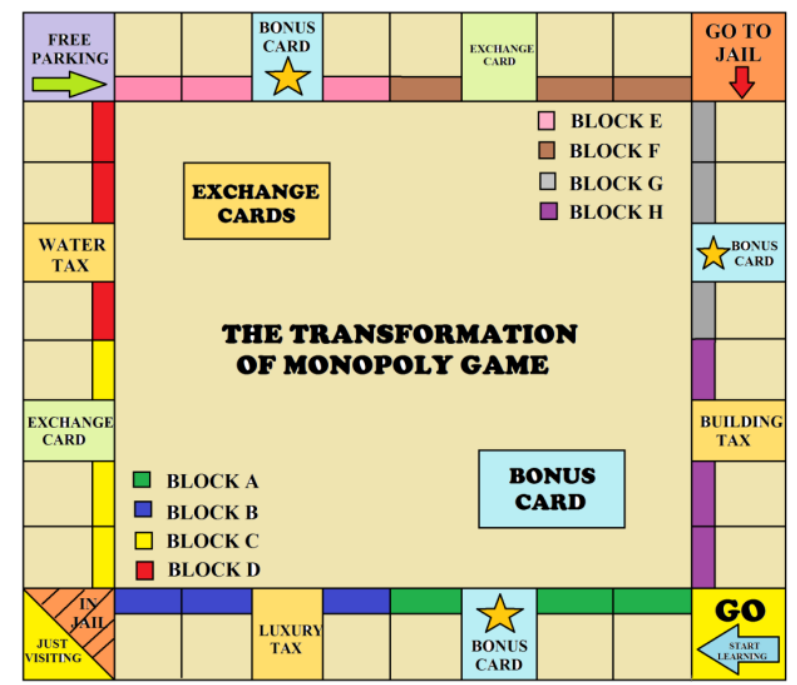

Figure 2. The Board Transformation Monopoly Game.

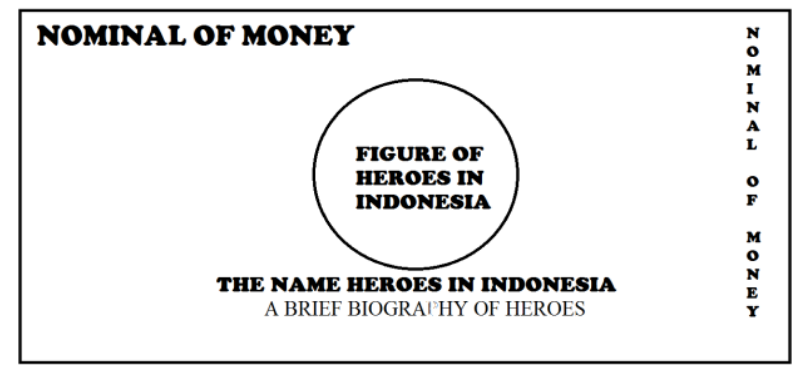

Figure 3. The Money Transformation Monopoly Game.

\section{BONUS CARD}

This card consists of a question if you can answer correctly then have the right to choose to get extra money or can advance 3 plots.

Example of question:

Give 4 example sentences using present

continuous

Figure 4. The Bonus Card.

\section{EXCRANGE CARD}

This card consists of several options, whether to save the card, replace it with money, or advance a few plots, or is useful for relief when entering prison and others .

\section{Example of question:}

Do you want change this card to be some money or just save it?

Figure 5. The Excange Card.

\section{1) The Board Transformation Monopoly Game}

Based on Figure 2. The Board Transformation Monopoly Game in the game plot which is traded are several

Tabel 1. The Results of Responses From Respondents Through Google Form. islands in Indonesia. There consists from some block, that are block A, B, C, D, E, F, G, and H. Each plot consists of at least one review question that has been given. Than, there have four big plot, that are plot to starting the game, plot in jail, plot free parking and plot go to jail. The other plots are bonus card, excahange card, laxury tax, water tax and buliding tax. The parts of some plots are areas to build buildings, four plots to start the game, plots to be imprisoned, free to go around one round, and head to prison. The plot for is plot for being subject to a water, luxury and building tax bill. While, the change of card plot and bonus cards to be utilized add to the profit. This game are played by the time, in each team can consists from 5-8 students.

\section{2) The Money Transformation Monopoly Game}

Based on figure 3. The Money Transformation Monopoly Game, the currency consists of images of heroes in Indonesia and brief biographies. The heroes are from Indonesian, they are the fighters who defend the nation from colonialism. It aims to make students not forget the history of their nation and continue to be a good person. It does not only learn one subject, but also learn several lessons in one learning model container. This game will increase students' interest and interest in the lessons.

\section{3) The Bonus Card}

Based on figure 4. The Bonus Card, this card consists of question, if the players can answer the correctly question they have the right choose to get extra money or can advance 3 plots. Every members in the team must answer the question. If they can't answer the question, they don't get the punishment, but they can't get the bonus of this card. The example of the question is like "Give four example sentences using present continuous!"

\section{4) The Exchange Card}

Based on figure 5. The Excange Card, this card consists of several option. Whether to save the card, replace it with the money, advance a few plots, or it is useful relief when entering in the jail and another options. The example question of the option is like "Do you want to change this card to be some money or just save it?"

\section{Result-2 (The Results of Responses From Respondents Through Google Form) \\ This is the data which from geting information to the respondents that are many respondents agree with the transformation monopoly game. Many argument from them, it can developt this reasearch as well as. The results of responses from the respondents through Google Fom is like:}




\begin{tabular}{|c|c|c|}
\hline No. & & Information \\
\hline & QUESTION & $\begin{array}{l}\text { Technological progress in this era can no longer be denied its existence. If this cannot be } \\
\text { resolved properly will it cause more negative impacts? }\end{array}$ \\
\hline & RESPONSES & $\begin{array}{l}83,3 \% \text { (Agree) } \\
16,7 \% \text { (Disagree) }\end{array}$ \\
\hline 2. & QUESTION & In your opinion, what are the negative and positive impacts of technological progress? \\
\hline & RESPONSES & $\begin{array}{l}\text { 1) Individual. } \\
\text { 2) The negative is so the children's enthusiasm for learning decreases and makes them lazy to } \\
\text { move. The positives make things easy and fast. }\end{array}$ \\
\hline
\end{tabular}

3) Negative: a lot of barbaric content, positive: what do you want me to have.

4) The negative impact is that it will be very detrimental and have a negative impact on users if not used properly. The positive impact is that it is very helpful in working on several activities to be completed effectively \& efficiently.

5) Negative impact: the emergence of an attitude of "better yourself", self-confidence decreases, the impact will occur if in an individual there is no motivation or sense to compete to be the best and of course by not dropping the time. For positive impact: a lot of it might be: D The first one is knowledge becoming wider, sense of exploration is higher, anything is easy (for those who are technology literate or can use it well), and maybe for individuals who are strongly opinionated individuals will definitely not be just staying in his comfort zone in other words will be more eager to do productive things in the real world.

6) The negative impact of being lazy, because everything is instant. The positive impact of humans is facilitated by technology.

7) The negatives are addictions.

8) Negative impact: inhibits the development of one's thinking power, children have learned because it is more concerned with playing games, damaging the eyes, the number of videos and photos of pornography and others. Positive impact: makes it easier to communicate remotely, makes it easier to find information, help complete money school assignments related to the internet, and others.

9) Add connection.

10) Make it easy for us to carry out buying and selling via online.

11) Negative impacts 1 . The erosion of cultural culture 2 . Dependence on positive technology 1 . Accelerating human performance effectively and efficiently 2 . Free market.

12) In its negative impact, the microeconomics is more difficult to develop until the positive impact increases stability in a developing country

3. QUESTION Due to the tendency to use technology often has an impact on technology addiction, this does not only occur among adolescents, adults and even children. So this can inhibit children's growth and development and thought power. Do you agree?

\begin{tabular}{cc}
\hline & RESPONSES \\
\hline 4. & QUESTION \\
\hline & RESPONSES
\end{tabular}
$83,3 \%$ (Agree) $16,7 \%$ (Disagree) In your opinion, what are the negative effects of technology addiction on children?

1) Poor social.

2) Can make children become independent and difficult to socialize in the real world.

3) Educate parents who introduce technology early on without being balanced by the impact of adequate use and supervision.

4) Often playing games, watching entertainment videos that are too excessive.

5) Many people who are lazy doing what they do because they may be comfortable, are more concerned with entertainment than education, and if it is difficult to separate opium in other words we must replace the technology with what children enjoy but still educate.

6) Children prefer to play gaget rather than socializing with their peers

7) The positives make it easier to get information, facilitate communication and can get positive content easily such as motivation, etc.

8) Negative impact: children have difficulty learning because they prefer to play games, damage the eyes because of inefficient use of mobile phones.

9) Poor social.

10) Kids prefer to play handphone games instead of playing outside with friends.

11) Interfering with the mindset and character of children

12) Lack of socialization will result in a monotonous life.

5. QUESTION One way to overcome technological addiction is to invite children to play outside and while learning. Here we suggest a prototype of a monopoly game reform that we named "The Transformation of Monopoly Games". This is a method/learning model that can be used by parents/teachers to evaluate the child or students to be able to play and while learning and can train their creative thinking. Do you agree the transformation of this game can reduce technological addiction in children? 


6. QUESTION
The workings of "The Transformation of Monopoly Games" are almost the same as monopoly
1) In the game plot which is traded are several islands in Indonesia;
1) Each plot consists of at least 1 review question that has been given;
3) Consists of change cards and bonus cards containing learning review questions;
4) Currency consists of images of heroes in Indonesia and brief biographies;
5) As well as several other advantages that can make students more interested in learning and
Do you agree this is effective for learning and reducing technology addiction in children?
(91,7\% (Agree)
8,3\% (Disagree)

\section{DISCUSSION}

This progress by social science experts is often referred to as the era of disruption, in this case an era in which all sectors come to feel the impact, both the health sector, economic, social, political, cultural and education sectors also feel the impact of the transition to digital progress. In this era of disruption, education can balance the demands of civilization. However, the world of education itself inevitably has to be able to adapt to changing times, education as a means of channeling knowledge so that people can balance themselves with the progress of this civilization. One of the causes of the decline of traditional games is the result of technological advancements which in turn create a variety of more interesting services, such as television, online games, video games and others. That can causes not only about tendency towards technology but can also reduce children's creative thinking. Then, it is necessary to encourage improvement of habits in children, especially in the learning process at school.

Based on the data which from geting information to the respondents that are many respondents agree with the transformation monopoly game. Many argument from them, it can develope this reasearch as well as. The results of responses from the respondents through Google Fom are varies. The argument from them about the negative effects of technology addiction on children, one oh them said "Many people who are lazy doing what they do because they may be comfortable, are more concerned with entertainment than education, and if it is difficult to separate opium in other words we must replace the technology with what children enjoy but still educate." and then others said "Negative impact: children have difficulty learning because they prefer to play games, damage the eyes because of inefficient use of mobile phones.

According at all in this research, it has a semitraditional learning media innovation to reduce the tendency of excessive use of technology in children. The transformation of menopoly game are one of media in learning process. The parts of transformation monopoly game look like, in each parts are a unity that cannot be separated there are:

1. The board game that consists of several blocks of regional blocks.
2. The miniature houses and people as movers and objects of the game.

3. The exchange cards and bonus cards.

4. The question sheet cards in each region.

5. Play money as a driver for the survival of the game.

This learning media innovation students can be more interested in learning, reduce student boredom, train creative thinking power and can reduce technological addiction in children.

\section{CONCLUSIONS}

The era of disruption is a period that has severe challenges to human life if humans are unable to adapt to changes, of course it will experience many difficulties in reducing the tide of life. Optimizing education with the use of "The Transformation of Monopoly Game" as an educational medium stimulates students to be more active and the material in it is more imprint and very effective and can be applied at all levels because this media is flexible can be developed according to the needs and the characteristics of students at each level and region. In this era of disruption, education can balance the demands of civilization. However, the world of education itself inevitably has to be able to adapt to changing times, education as a means of channeling knowledge so that people can balance themselves with the progress of this civilization. This learning media innovation students can be more interested in learning process, reduce student boredom, creative thinking power and can reduce technological addiction in children.

\section{ACKNOWLEDGEMENTS}

Praise God Almighty, for the presence of plenty of mercy and his grace, so that the writer can complete the thesis with the title "The Transformation Of Monopoly Game: Learning Media To Improve Students' Creativity And Interest In Learning". This meet one of the research studies in order to obtained in Faculty of Science and Technology, Islamic State University of Sunan Kalijaga Yogyakarta. May Allah SWT always bestow grace, 
health, gifts and blessings in the world and in the hereafter over good that has been given to the author and the many people who have contributed to this research. The final word the author realized that in the writing of this writingis still far from perfection. Therefore, the authors invoke suggestions and criticisms which is build for the sake of perfection and may be useful for all of us.

\section{REFERENCES}

Harto, K. (2018). Tantangan Dosen PTKI di Era Industri 4.0. Journal of Educational Thought and Research, 16(1).
Liu, C,. \& Xu,. X. (2017). Cyber-Physical Machine Tool - the Era of Machine Tool 4.0. Science Direct, 63. Accessed from https://reader.elsevier.com/reader/sd/pii/S221282711730224X ?token= DOI: 10.1016/j.procir.2017.03.078

Munawaroh, H. (2017). Pengembangan Model Pembelajaran dengan Permainan Tradisional Engklek Sebagai Sarana Stimulasi Perkembangan Anak Usia Dini. Journal of Obsession: Journal of Early Childhood Education, 1(2).

Suhariyanto. (2018). Potret Pendidikan Indonesia Statistik Indonesia 2018. Jakarta: Badan Pusat Statistik.

Sudrajat. Taat Wulandari. \& Agustina Tri Wijayanti. (2015). Muatan Nila-nilai Karakter Melalui Permainan Tradisional di PAUD Among Siwi, Panggungharjo, Sewon, Bantul. JIPSINDO, 2(1). 
THIS PAGE INTENTIONALLY LEFT BLANK 